\title{
Epidermal growth factor receptor kinase activity is required for gap junction closure and for part of the decrease in ovarian follicle cGMP in response to $\mathrm{LH}$
}

\author{
Rachael P Norris, Marina Freudzon, Viacheslav O Nikolaev ${ }^{1}$ and Laurinda A Jaffe \\ Department of Cell Biology, University of Connecticut Health Center, Farmington, Connecticut 06032, USA and \\ ${ }^{1}$ Institute of Pharmacology and Toxicology, University of Würzburg, D-97078 Würzburg, Germany \\ Correspondence should be addressed to L A Jaffe; Email: Ijaffe@neuron.uchc.edu
}

\begin{abstract}
The meiotic cell cycle in mouse oocytes is arrested in prophase, and then restarted when LH acts on the surrounding granulosa cells. The granulosa cells keep meiosis arrested by providing a source of cGMP that diffuses into the oocyte through gap junctions, and LH restarts the cell cycle by closing the junctions and by decreasing granulosa cell cGMP, thus lowering oocyte cGMP. Epidermal growth factor receptor (EGFR) activation is an essential step in triggering LH-induced meiotic resumption, but its relationship to the cGMP decrease in the follicle is incompletely understood, and its possible function in causing gap junction closure has not been investigated. Here, we use EGFR agonists (epiregulin and amphiregulin) and an EGFR kinase inhibitor (AG1478) to study the function of the EGFR in the signaling pathways leading to the release of oocytes from prophase arrest. Our results indicate that the EGFR kinase contributes to LH-induced meiotic resumption in two different ways. First, it is required for gap junction closure. Second, it is required for an essential component of the decrease in follicle cGMP. Our data show that the EGFR kinase-dependent component of the cGMP decrease is required for $\mathrm{LH}$-induced meiotic resumption, but they also indicate that an as yet unidentified pathway accounts for a large part of the cGMP decrease.
\end{abstract}

Reproduction (2010) 140 655-662

\section{Introduction}

The mammalian ovarian follicle is comprised of multiple layers of granulosa cells enclosing a central oocyte, which is arrested in prophase of meiosis until LH acts on the outer granulosa cells to restart the cell cycle (Eppig et al. 2004, Jaffe \& Norris 2010). In the mouse preovulatory follicle, all of the granulosa cells and the oocyte are interconnected by gap junctions (Norris et al. 2008), and the presence of the granulosa cells with open gap junctions is essential for maintaining the oocyte in meiotic prophase arrest. If the oocyte is removed from the follicle (Pincus \& Enzmann 1935), or if the gap junctions are closed pharmacologically (Piontkewitz \& Dekel 1993, Sela-Abramovich et al. 2006, Norris et al. 2008), the oocyte resumes meiosis.

The gap junctions provide a direct connection by which cGMP enters the oocyte from the granulosa cells, and in the oocyte, cGMP inhibits phosphodiesterase $3 \mathrm{~A}$, thus keeping cAMP high and maintaining meiotic arrest (Norris et al. 2009, Vaccari et al. 2009). cAMP is generated in the oocyte by a constitutively active $\mathrm{G}_{\mathrm{s}}$-linked receptor, GPR3 in mice or GPR12 in rats (Mehlmann et al. 2004, Hinckley et al. 2005, Ledent et al. 2005, Mehlmann 2005). High cAMP in the oocyte maintains meiotic arrest at least in part by activating protein kinase $A$, which phosphorylates the phosphatase CDC25B; this results in sequestration of CDC25B in the cytoplasm, such that it cannot dephosphorylate and activate the kinase CDK1 in the nucleus, which directly controls the prophase-to-metaphase transition (Oh et al. 2010). CDK1 activity also depends on a regulatory cyclin B1 subunit, and by unknown means, high cAMP prevents the accumulation of cyclin B1 in the nucleus (Marangos \& Carroll 2004, Holt et al. 2010).

$\mathrm{LH}$ receptor activation in the outer granulosa cells acts to reverse the inhibition of CDK1 in the oocyte by reducing the influx of cGMP from the granulosa cells into the oocyte. $\mathrm{LH}$ reduces CGMP influx both by causing the gap junctions to close (Sela-Abramovich et al. 2006, Norris et al. 2008) and by causing cGMP in the granulosa cells to decrease (Norris et al. 2009, Vaccari et al. 2009; see also Davis et al. 1986, Hubbard 1986, Törnell et al. 1991). Both of these LH actions have the consequence of lowering CGMP in the oocyte, thus lowering cAMP, activating CDK1, and restarting the meiotic cell cycle, which is characterized by the breakdown of the nuclear envelope between 2 and $4 \mathrm{~h}$ after $\mathrm{LH}$ exposure. $\mathrm{LH}$ acts 
on a G-protein-coupled receptor (Jaffe \& Norris 2010), but how this results in gap junction closure and the cGMP decrease in the mouse ovarian follicle is not well understood.

One important link between $\mathrm{LH}$ receptor activation in the outer granulosa cells and meiotic resumption in the oocyte is the rapid synthesis (Park et al. 2004) and proteolytic release from the granulosa cell surface (Ashkenazi et al. 2005, Andric \& Ascoli 2008, Panigone et al. 2008) of the epidermal growth factor receptor (EGFR) ligands epiregulin and amphiregulin. EGFR kinase activity in the follicle increases by $30 \mathrm{~min}$ after LH application (Panigone et al. 2008). Treatment of isolated follicles with EGFR ligands causes meiosis to resume (Dekel \& Sherizly 1985, Park et al. 2004, Ashkenazi et al. 2005), and AG1478, which inhibits EGFR kinase activity (Levitzki \& Gazit 1995, Panigone et al. 2008), inhibits meiotic resumption in response to LH (Park et al. 2004, Ashkenazi et al. 2005). In addition, follicles from mice that express a mutated EGFR kinase with reduced activity, or that lack the EGFR ligands epiregulin or amphiregulin, show reduced meiotic resumption in response to $\mathrm{LH}$ (Hsieh et al. 2007). EGFRs are located on both mural granulosa and cumulus cells, but not on the oocyte (Downs et al. 1988, Park et al. 2004, Panigone et al. 2008, Su et al. 2010), supporting the concept that the release of epiregulin and amphiregulin from the outer granulosa cells, where the $\mathrm{LH}$ receptors are located, functions to propagate the $\mathrm{LH}$ signal into the follicle interior.

A previous study has shown that activation of the EGFR with amphiregulin or epiregulin lowers granulosa cell cGMP, and that the decrease in granulosa cell cGMP in response to $\mathrm{LH}$ can be reduced by inhibiting the EGFR kinase with AG1478 (Vaccari et al. 2009). Here, we further investigate the function of the EGFR kinase in causing the cGMP decrease, and also examine its function in causing gap junction closure. Our data indicate that while EGFR kinase activity is required for the LH-induced closure of gap junctions, an as yet unidentified pathway accounts for a large part of the cGMP decrease. However, the EGFR kinase-dependent component of the cGMP decrease is required for $\mathrm{LH}$-induced meiotic resumption.

\section{Results and Discussion}

\section{Magnitude and time course of the cGMP decrease in response to $\mathrm{LH}$}

Two previous studies have shown that cGMP in isolated mouse follicles decreases in response to $\mathrm{LH}$, but the basal cGMP concentrations and the magnitudes of the decrease differed (Norris et al. 2009, Vaccari et al. 2009). Therefore, to establish a baseline for subsequent experiments, we determined the magnitude and time course of the cGMP decrease upon LH application for the experimental conditions used here. Measurements were made using an ELISA method, and concentrations were calculated using an estimated value of $20 \mathrm{nl}$ for the cellular volume of an isolated follicle (see Materials and Methods). Because the volume was not known exactly, the following concentrations should be considered approximations. The mean value for basal cGMP was $\sim 3 \mu \mathrm{M}$, and this decreased to $\sim 500 \mathrm{nM}$ at 20 min after LH application; cGMP then continued to decrease, reaching $\sim 100 \mathrm{nM}$ at $1 \mathrm{~h}$ and $\sim 30 \mathrm{nM}$ at $5 \mathrm{~h}$ (Fig. 1 ).

The measurements reported here as well as those in our previous study (Norris et al. 2009) indicate that at $1 \mathrm{~h}$ after LH application, GMP has decreased to $\sim 4 \%$ of the basal level, whereas another study (Vaccari et al. 2009) reported a smaller decrease to $39 \%$. In addition, while we found that most of the cGMP decrease had occurred by 20 min after LH application, Vaccari et al. first detected the cGMP decrease at $1 \mathrm{~h}$, with no change seen at $30 \mathrm{~min}$. Interestingly, a study of rat granulosa cells in primary culture showed a decrease in CGMP as early as 3 min after applying LH (Davis et al. 1986).

\section{Activation of the EGFR causes a decrease in follicle cGMP}

To investigate to what extent the EGFR kinase contributes to the LH-induced decrease in follicle cGMP, we first measured cGMP in response to an EGFR ligand. The concentrations of epiregulin and amphiregulin proteins in the extracellular space of the follicle after LH exposure are unknown, so we used a concentration of epiregulin $(100 \mathrm{nM})$ that has been previously found to maximally stimulate nuclear envelope breakdown when applied to isolated follicles (Park et al. 2004). We confirmed the previous finding that $100 \mathrm{nM}$ epiregulin stimulates meiotic resumption to the same extent as LH (Fig. 2). Approximately $90 \%$ of oocytes underwent nuclear envelope breakdown by $4 \mathrm{~h}$.

Some but not all of the cGMP decrease that occurred in response to $\mathrm{LH}$ also occurred when follicles were treated with epiregulin. The mean concentration of cGMP was $\sim 600 \mathrm{nM}$ following a $1 \mathrm{~h}$ treatment with $100 \mathrm{nM}$ epiregulin versus $\sim 100 \mathrm{nM}$ cGMP in response to LH (Fig. 3A).

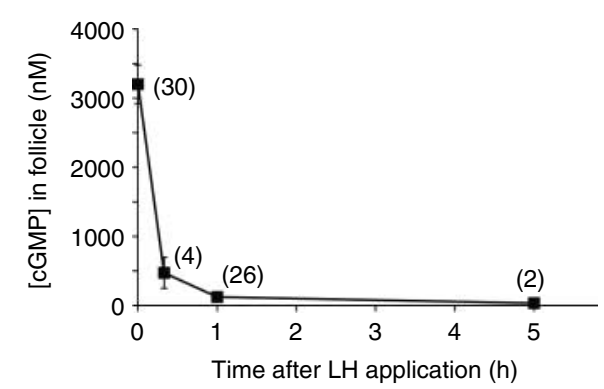

Figure 1 cGMP in mouse ovarian follicles at various times after applying LH. Bars indicate mean \pm S.E.M., and numbers in parentheses indicate the number of samples. 


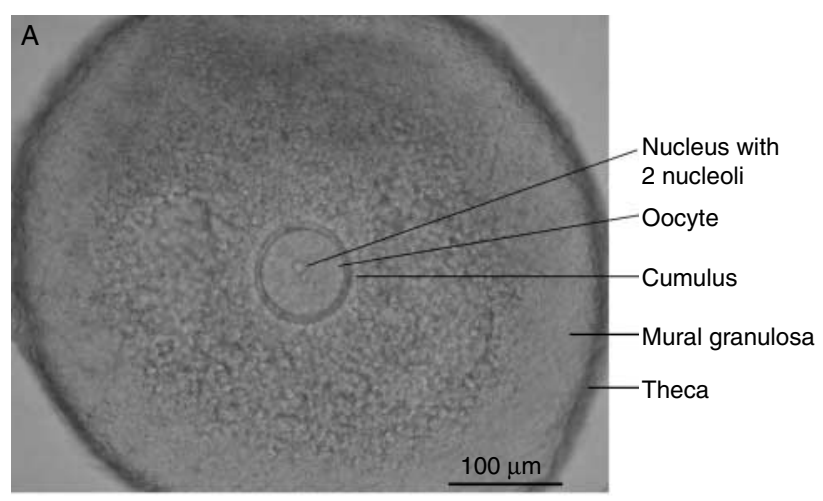

isolated oocytes (Park et al. 2004, and Supplementary Figure 1, see section on supplementary data given at the end of this article).

At a concentration of $500 \mathrm{nM}, \mathrm{AG} 1478$ had only a partial inhibitory effect on the $\mathrm{LH}$-induced cGMP decrease (Fig. 3A). At $1 \mathrm{~h}$ after applying $\mathrm{LH}$ in the presence of AG1478, cGMP had decreased to $\sim 500 \mathrm{nM}$, corresponding to $\sim 15 \%$ of the basal level. This was significantly different from the $\sim 100 \mathrm{nM}$ level attained at $1 \mathrm{~h}$ after $\mathrm{LH}$

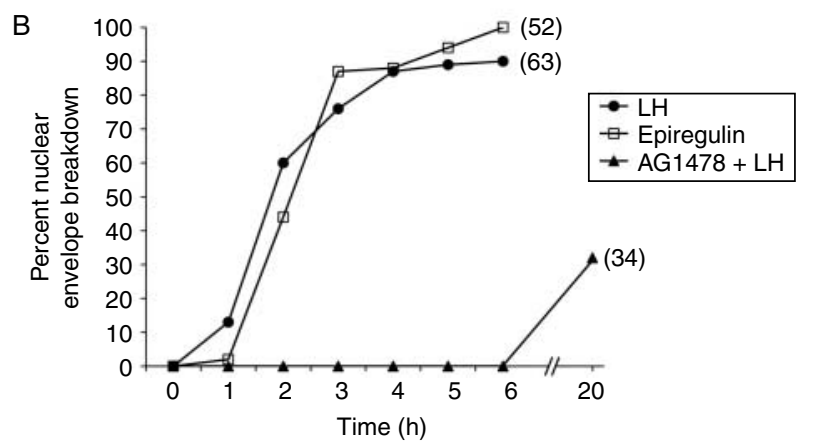

Figure 2 Observation of the time course of nuclear envelope breakdown in intact follicle-enclosed oocytes in response to an EGFR agonist (epiregulin), or to $\mathrm{LH}$ in the presence or absence of an EGFR kinase inhibitor (AG1478). (A) A mouse follicle on a Millicell membrane; the prophase-arrested nucleus and two nucleoli are visible. (B) Nuclear envelope breakdown at various times after treatment of follicles with LH (350 nM), epiregulin (100 nM), or AG1478 (500 nM) for $1 \mathrm{~h}$ followed by AG1478 + LH. Numbers in parentheses indicate the number of follicles.

\section{The EGFR kinase inhibitor AG1478 only partially inhibits the cGMP decrease in response to $L H$}

To examine whether EGFR kinase activation is required for LH stimulation of the cGMP decrease, we used the selective EGFR kinase inhibitor AG1478. In vitro, AG1478 inhibits EGFR kinase activity with an $\mathrm{IC}_{50}$ of 3 nM (Levitzki \& Gazit 1995). In follicles stimulated with LH, 500 nM AG1478 completely inhibits LH-induced EGFR phosphorylation on tyrosine 1068, one of several tyrosines that are phosphorylated in response to EGFR activation; this indicates that $\mathrm{LH}$ does not detectably increase EGFR activation under these conditions (Panigone et al. 2008).

As previously reported (Park et al. 2004, Ashkenazi et al. 2005), AG1478 had an inhibitory effect on nuclear envelope breakdown in response to $\mathrm{LH}$. Under our conditions, $500 \mathrm{nM}$ AG1478 completely inhibited nuclear envelope breakdown in response to $\mathrm{LH}$ when observed at $6 \mathrm{~h}$, although $\sim 30 \%$ of oocytes had resumed meiosis when observed at $20 \mathrm{~h}$ (Fig. 2B). The meiosis-inhibitory effect of AG1478 is on signaling in the granulosa cells, rather than the oocyte, since AG1478 does not inhibit spontaneous meiotic resumption in

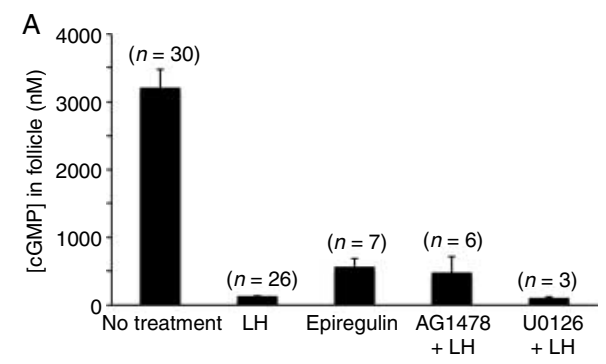

B
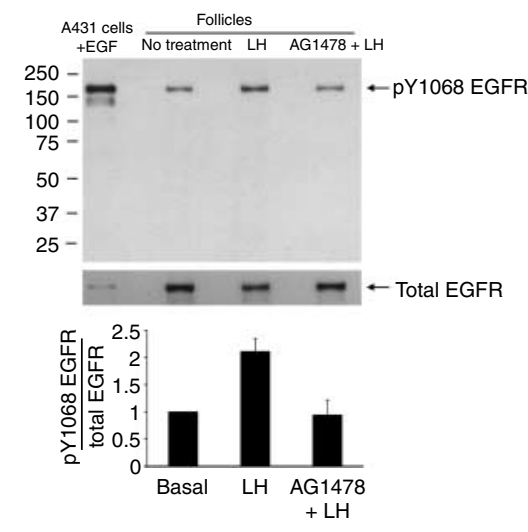

Figure 3 cGMP in follicles under experimental conditions affecting EGFR kinase or MAP kinase activity. (A) Measurement of follicle cGMP under the following conditions: no treatment (basal), $1 \mathrm{~h} \mathrm{LH}(350 \mathrm{nM})$, $1 \mathrm{~h}$ epiregulin (100 nM), $1 \mathrm{~h} \mathrm{AG1478} \mathrm{(500} \mathrm{nM)} \mathrm{followed} \mathrm{by} 1 \mathrm{~h}$ AG1478+LH, 1 h U0126 (10 $\mu \mathrm{M})$ followed by 1 h U0126 + LH. Bars indicate mean \pm S.E.M., and numbers in parentheses indicate the number of samples. The cGMP concentration after $100 \mathrm{nM}$ epiregulin treatment is significantly different from that for basal and LH conditions $(P<0.0001)$. Likewise, the cGMP concentration after AG1478+LH treatment is significantly different from that for basal $(P<0.0001)$ and $\mathrm{LH}(P=0.01)$ conditions. The cGMP concentration after $\cup 0126+\mathrm{LH}$ treatment is not significantly different from that after $\mathrm{LH}$ alone $(P=0.7)$, but is significantly different from the basal concentration $(P=0.0004)$. (B) Demonstration that in follicles stimulated with $\mathrm{LH}$, treatment with 500 nM AG1478 as described above reduces EGFR phosphorylation on tyrosine 1068 to a level that is indistinguishable from the basal level without LH. Twenty micrograms of follicle lysates and $2 \mu \mathrm{g}$ of EGF-treated AG431 cells were used for immunoblotting with an antibody specific for pY1068 EGFR and then with an antibody specific for total EGFR. The graph shows the ratio of the intensities of the $\sim 170 \mathrm{kDa}$ band measured with the two antibodies, normalized to the no treatment condition (mean \pm s.D. for two independent experiments). Since the follicles were cultured for $24 \mathrm{~h}$ in the absence of EGFR ligands or serum prior to preparing the samples, the basal signal seen with the pY1068 antibody is probably not due to EGFR kinase activity; it could result from phosphorylation of the EGFR by other kinases or to cross reactivity of the antibody with non-phosphorylated EGFR. 
in the absence of AG1478. However, the presence of AG1478 did not restore cGMP to the basal level of $\sim 3 \mu \mathrm{M}$ measured in the absence of $\mathrm{LH}$; the values for the basal cGMP concentration and that at $1 \mathrm{~h}$ after $\mathrm{LH}+500 \mathrm{nM}$ AG1478 were significantly different (Fig. 3A).

The incomplete inhibition of the LH-induced cGMP decrease by AG1478 did not appear to be due to incomplete inhibition of the EGFR kinase activity, since $500 \mathrm{nM}$ AG1478 prepared from the same stock solution as used for the cGMP measurements reduced LH-stimulated phosphorylation of the EGFR on tyrosine 1068 to a level that was indistinguishable from the basal level without LH (Fig. 3B). Thus, although epiregulin is sufficient to cause $\sim 80 \%$ of the cGMP decrease in the follicle in response to LH, EGFR activity is not required for most of the LH-induced cGMP decrease. These findings support the concept that two separate and partially redundant mechanisms contribute to the decrease in cGMP in response to $\mathrm{LH}$.

\section{Inhibition of the activation of MAP kinase with $U 0126$ has no inhibitory effect on the cGMP decrease in response to $\mathrm{LH}$}

One important consequence of EGFR kinase activation in the ovarian follicle is the activation of MAP kinase (Panigone et al. 2008). Therefore, we investigated the effect of inhibiting MAP kinase activation on the $\mathrm{LH}$-induced cGMP decrease in the follicle. To do this, we used U0126, an inhibitor of the kinase (MAP kinase kinase, or MEK) that activates MAP kinase. U0126 at a concentration of $10 \mu \mathrm{M}$, which has previously been demonstrated to fully inhibit MAP kinase activation in response to LH (Norris et al. 2008), did not have any inhibitory effect on the cGMP decrease in response to $\mathrm{LH}$ (Fig. 3A). Thus, the cGMP decrease in response to $\mathrm{LH}$, including its EGFR kinase-dependent component, occurs by a pathway other than MAP kinase activation. In contrast, $10 \mu \mathrm{M} \cup 0126$ completely inhibits gap junction closure in response to LH (Norris et al. 2008).

\section{Activation of the EGFR causes gap junction closure}

To investigate whether gap junction closure in response to $\mathrm{LH}$ is mediated by activation of the EGFR kinase, we first compared gap junction permeability after applying epiregulin or LH. Gap junction permeability was assessed by injecting a fluorescent tracer into the oocyte, and 20 min later, measuring the ratio of fluorescence in the mural granulosa cells over that in the inner cumulus cells (Norris et al. 2008). Compared to the ratio in untreated follicles, $1 \mathrm{~h}$ treatments with $\mathrm{LH}$ and $100 \mathrm{nM}$ epiregulin caused decreases to 9 and $32 \%$ of the basal level respectively (Fig. 4). Even when the concentration of EGFR agonist was increased 20 times by applying $1 \mu \mathrm{M}$ epiregulin $+1 \mu \mathrm{M}$ amphiregulin, gap junction closure was less complete than that observed with $\mathrm{LH}$ application (Fig. 4), but it is unknown how well externally applied EGFR agonists penetrate throughout the follicle. Our results suggest that the stimulation of meiotic resumption by externally applied EGFR ligands (see Introduction and Fig. 2) is a consequence of partial closure of gap junctions and a partial decrease in granulosa cell cGMP, acting together to lower oocyte cGMP.
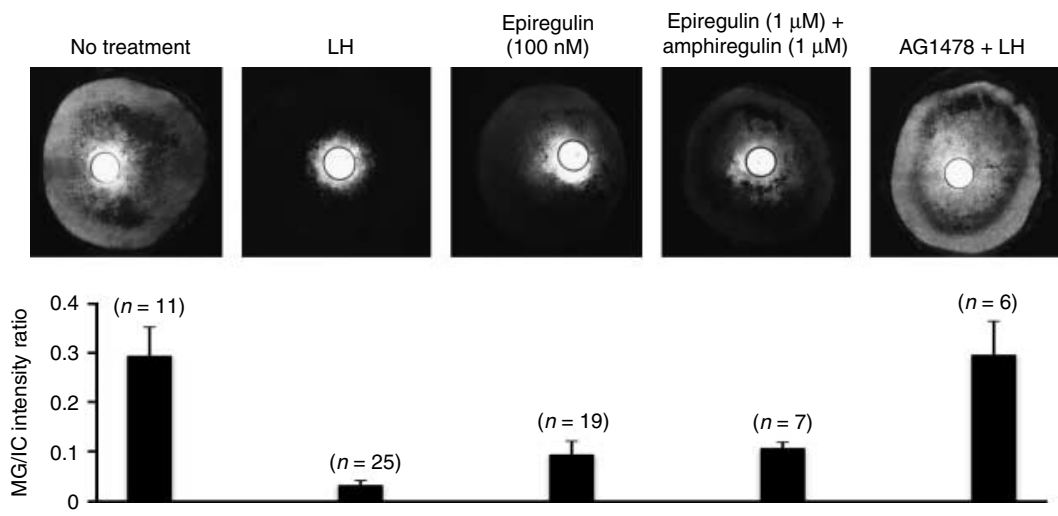

Figure 4 Gap junction communication in follicles under experimental conditions affecting EGFR kinase activity. Gap junction communication was assessed by injecting the oocyte with Alexa Fluor 350 and imaging the follicle 20 min later. (A) Images of follicles that were treated as follows prior to injection of the fluorescent tracer: no treatment (basal), $1 \mathrm{~h} \mathrm{LH}(350 \mathrm{nM}), 1 \mathrm{~h}$ epiregulin $(100 \mathrm{nM}), 1 \mathrm{~h}$ epiregulin $(1 \mu \mathrm{M})+\mathrm{amphiregulin}(1 \mu \mathrm{M}), 1 \mathrm{~h}$

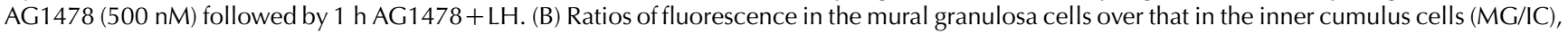
at $20 \mathrm{~min}$ after injection, for each of the conditions indicated in (A). Bars indicate mean \pm S.E.M., and numbers in parentheses indicate the number of follicles. The MG/IC ratio after treatment with $100 \mathrm{nM}$ epiregulin is significantly different from that after $\mathrm{LH}(P=0.05)$ and from the basal ratio $(P=0.005)$. Likewise, the $\mathrm{MG} / \mathrm{IC}$ ratio after treatment with $1 \mu \mathrm{M}$ epiregulin $+1 \mu \mathrm{M}$ amphiregulin is significantly different from that after $\mathrm{LH}$ $(P=0.0003)$; the difference from the basal ratio is marginally significant $(P=0.06)$. The MG/IC ratio for AG1478+LH is significantly different from that for $\mathrm{LH}(P<0.0001)$, but not from the basal ratio $(P=1.0)$. 


\section{The EGFR kinase inhibitor AG1478 inhibits gap junction closure in response to $\mathrm{LH}$}

We next examined the effect on $\mathrm{LH}$-induced gap junction closure of inhibiting the EGFR kinase with AG1478. In the presence of $500 \mathrm{nM}$ AG1478, gap junction permeability after LH application was indistinguishable from that in an untreated follicle (Fig. 4). It should be noted, however, that partial closure of gap junctions might not have been detected by the method used here. These results indicate that EGFR activation is an essential factor in causing gap junction closure in response to $\mathrm{LH}$, but leave open the possibility that other signaling pathways contribute as well. The conclusion that EGFR activation is an important factor in causing gap junctions to close in response to $\mathrm{LH}$ is supported by a recent report that ovaries from mice with reduced EGFR activity show reduced phosphorylation of gap junction protein alpha 1 (GJA1, also known as connexin 43, CX43) in response to LH (Andric et al. 2010).

An alternative interpretation of these results is that non-specific effects of AG1478 could contribute to its inhibitory effect on gap junction closure (and on the cGMP decrease). An extensive characterization of the specificity of AG1478 has not been previously published, but information on this question was made available by the National Centre for Protein Kinase Profiling (MRC Protein Phosphorylation Unit, University of Dundee, Scotland, UK). The $\mathrm{IC}_{50}$ for $\mathrm{AG} 1478$ was $>1 \mu \mathrm{M}$ for 101 out of the 110 kinases tested (see Supplementary Table 1, see section on supplementary data given at the end of this article). Although in vivo inhibitory concentrations cannot be predicted from the in vitro data, the in vitro inhibitory concentrations for all of these other kinases were much greater than that for the EGFR $\left(\mathrm{IC}_{50}=3 \mathrm{nM}\right.$, Levitzki \& Gazit 1995). Importantly, the MAP kinases ERK1 and ERK2 were not inhibited by AG1478. Thus, although non-specific effects have not been absolutely excluded, the actions of $500 \mathrm{nM}$ AG1478 on the LH-induced gap junction closure and follicle cGMP decrease are most likely due to inhibition of the EGFR kinase.

\section{Comparison with previous studies}

The results described here indicate that the EGFR kinase contributes to $\mathrm{LH}$-induced meiotic resumption both by causing gap junction closure and by causing an essential component of the decrease in follicle cGMP. They also indicate that an as yet unidentified pathway accounts for a large part of the cGMP decrease. Although both this study and a previous study (Vaccari et al. 2009) support the conclusion that the EGFR kinase has a role in causing the cGMP decrease in response to $\mathrm{LH}$, the two studies differ on the issue of whether EGFR activation is solely responsible. While we found that $500 \mathrm{nM}$ AG1478 had only a partial inhibitory effect on the
cGMP decrease, the Vaccari et al. study reported that at $500 \mathrm{nM}$, AG1478 completely inhibited the cGMP decrease in response to $\mathrm{LH}$.

The causes of the differences in some of the results reported here and by Vaccari et al. are unknown, but differences in the strain of mouse, the methods of follicle culture, and/or other methodological differences could be critical. One possible factor is that the mean value for basal cGMP reported here $(\sim 60 \mathrm{fmol} /$ follicle $)$ was somewhat greater than that in the Vaccari et al. study ( $\sim 18 \mathrm{fmol} /$ follicle), possibly due to the methods of sample preparation. While Vaccari et al. froze the follicles, and only after defrosting processed them to inactivate cGMP phosphodiesterases, we prepared samples from unfrozen follicles. In preliminary experiments in which we used frozen follicles, our measurements of basal cGMP were $\sim 10 \%$ of the values obtained in subsequent experiments with follicles processed without prior freezing (Supplementary Figure 2, see section on supplementary data given at the end of this article). Possible loss of cGMP during sample processing could contribute to why Vaccari et al. observed complete inhibition of the LH-induced cGMP decrease by AG1478. If a non-EGFR kinase-dependent cGMP decrease occurred during sample preparation, it could mask a non-EGFR kinase-dependent component of the cGMP decrease that occurs in response to LH. Likewise, such an effect could contribute to the smaller percent decrease in follicle cGMP in response to LH reported by Vaccari et al. and to why an early decrease in CGMP was not detected. Other unknown factors may also be important.

Despite these differences, our data support the general conclusion that EGFR signaling is important for both pathways leading to meiotic resumption in response to $\mathrm{LH}$. The physiological significance of the EGFR kinasedependent component of the CGMP decrease is indicated by comparing the effects of U0126 and AG1478 on responses to $\mathrm{LH}$. Both inhibitors prevent gap junction closure (Fig. 4, and Norris et al. 2008), but only AG1478 has an inhibitory effect on the cGMP decrease (Fig. 3A). Correspondingly, $\mathrm{LH}$ causes meiotic resumption in the presence of U0126 (Su et al. 2003, Norris et al. 2008), but not in the presence of AG1478 (see Introduction and Fig. 2). Thus, to decrease cGMP sufficiently to cause meiotic resumption, EGFR signaling is essential.

\section{Unanswered questions}

Activation of MAP kinase causes the closure of gap junctions in response to LH by phosphorylating GJA1 (Sela-Abramovich et al. 2005, Norris et al. 2008), and MAP kinase activation in the follicle in response to $\mathrm{LH}$ depends strongly, but not entirely, on EGFR kinase activity (Panigone et al. 2008). Likewise, GJA1 phosphorylation depends strongly on EGFR kinase activity (Andric et al. 2010). These results indicate that the EGFR 
kinase acts to cause gap junction closure by initiating a signaling pathway that results in MAP kinase phosphorylation of GJA1. However, MAP kinase activation does not account for the cGMP decrease in response to LH-induced EGFR activation, since the LH-induced decrease in cGMP in the follicle occurs independently of MAP kinase. It remains to be determined how other consequences of EGFR kinase activation contribute to the cGMP decrease in the follicle (Fig. 5).

Our findings support the conclusion that pathways other than EGFR kinase activation also function to cause the $\mathrm{LH}$-induced cGMP decrease in the follicle. In particular, while the $\mathrm{LH}$-induced rise in cAMP in the mural granulosa cells leads to EGFR activation (Panigone et al. 2008), cAMP elevation may have other EGFRindependent effects. It also remains to be determined whether other EGFR-independent consequences of the

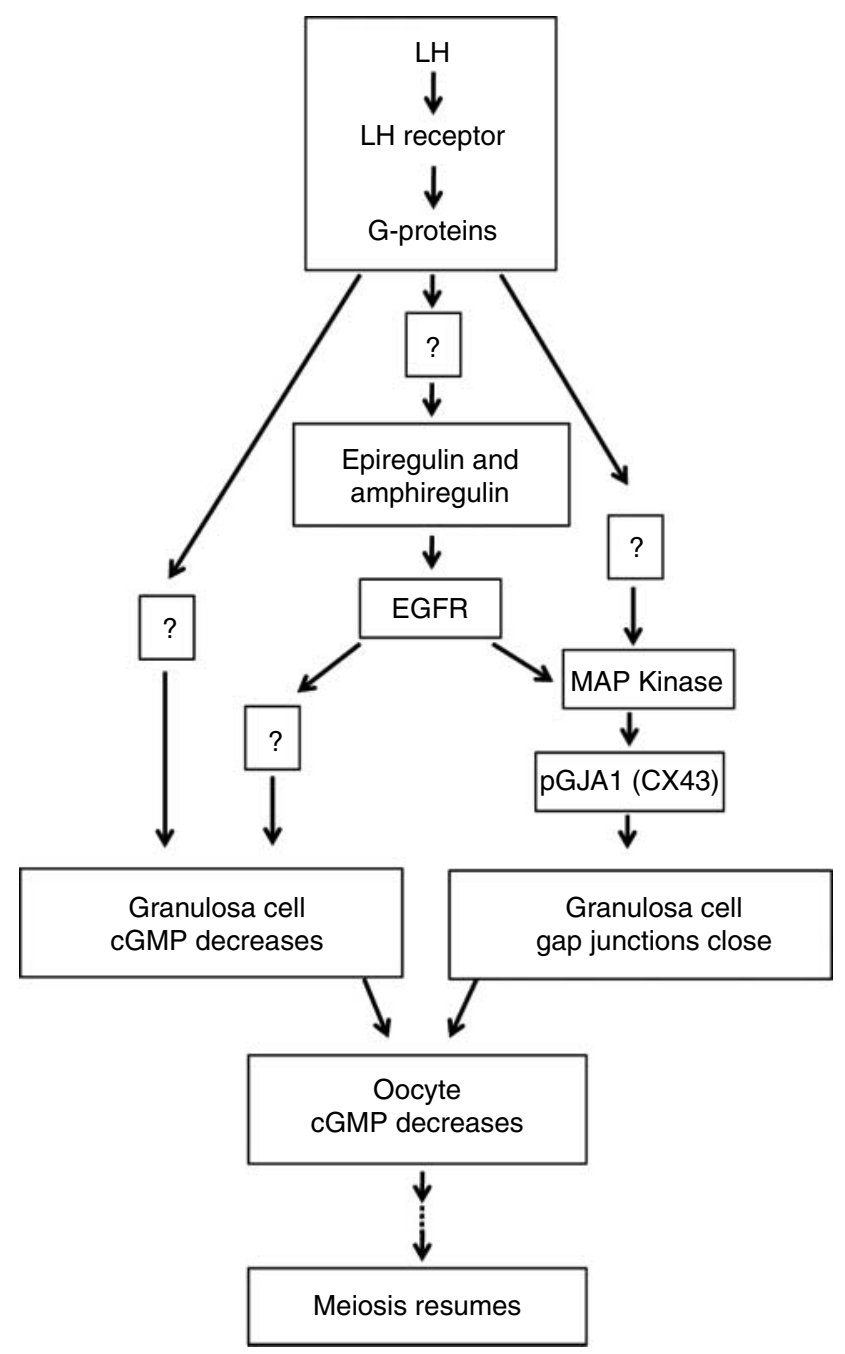

Figure 5 Some of the known and unknown components of the signaling network linking $\mathrm{LH}$ receptor and EGFR receptor activation in the granulosa cells to the decrease in CGMP in the oocyte that leads to resumption of meiosis. activation of G-proteins by $\mathrm{LH}$ are required for the cGMP decrease, and how these pathways lead to inhibition of a guanylyl cyclase and/or activation of a cGMP phosphodiesterase in the follicle (Fig. 5). Finally, much remains to be learned about how activation of the $\mathrm{LH}$ receptor causes the synthesis of epiregulin and amphiregulin precursors and the proteolytic cleavage of these peptides from the granulosa cell surface, leading to the activation of the EGFR (Fig. 5).

\section{Materials and Methods}

\section{Hormones and reagents}

FSH (ovine) and LH (ovine) were obtained from A F Parlow (National Hormone and Peptide Program, Torrance, CA, USA). Epiregulin and amphiregulin (mouse) were obtained from R\&D Systems (Minneapolis, MN, USA). Alexa Fluor 350 was obtained from Invitrogen (\#A10439). AG1478 and U0126 were obtained from EMD Chemicals (La Jolla, CA, USA) and were dissolved in DMSO at 10 and $100 \mathrm{mM}$ respectively; aliquots were stored at $-80^{\circ} \mathrm{C}$.

\section{Mice and follicle culture}

B6SJLF1 mice, 23-24 days old, were obtained from The Jackson Laboratories (Bar Harbor, ME, USA). All procedures involving mice were approved by the University of Connecticut Health Center Animal Care Committee. The culture medium was as previously described (Norris et al. 2008), except that the MEM $\alpha$ (\#41061029, Invitrogen) contained no phenol red, and contained $3 \mathrm{mg} / \mathrm{ml}$ BSA (MP Biomedicals, Solon, OH, USA) instead of fetal bovine serum. Antral follicles with diameters from $\sim 320$ to $\sim 400 \mu \mathrm{m}$ were dissected and placed on Millicell culture plates (PICMORG50, Millipore, Billerica, MA, USA) with 12-16 follicles per plate, at $37^{\circ} \mathrm{C}$, with $5 \%$ $\mathrm{CO}_{2}$. The follicles were cultured for $24-32 \mathrm{~h}$ before use to allow the expression of $\mathrm{LH}$ receptors in response to the $\mathrm{FSH}$ in the medium, and to allow the follicles to flatten on the Millicell membranes, improving their optical clarity.

Under these conditions, we could easily see the oocyte nucleus with its one or two nucleoli through the follicle wall by observing the culture dish from the top with a $20 \times / 0.4$ NA long working distance objective (LD Achroplan \#4408 44; Carl Zeiss Inc., Thornwood, NY, USA; Fig. 2A). Follicles were checked at $24 \mathrm{~h}$ after dissection, and only those that were healthy and prophase-arrested were used for experiments. For determination of the time course of meiotic resumption, we excluded any experiment in which $<70 \%$ of control follicles treated with $\mathrm{LH}$ had undergone nuclear envelope breakdown at $5 \mathrm{~h}$, since this was considered to be an indication that unknown aspects of the culture conditions were not optimal on that day. $\mathrm{LH}$ was used at a concentration of $350 \mathrm{nM}(10 \mu \mathrm{g} / \mathrm{ml})$.

\section{cGMP ELISA assays}

cGMP in follicles was assayed using an ELISA kit (\#CG200, Sigma-Aldrich), as described by Norris et al. (2009). To prepare the samples, 12-20 follicles on a Millicell membrane were 
washed twice with calcium- and magnesium-free PBS (\#10010-023, Invitrogen) and then transferred from the Millicell membrane to a microfuge tube. A volume of $100 \mu \mathrm{l}$ of $0.1 \mathrm{M} \mathrm{HCl}$ was added, and the follicles were lysed by applying $\sim 30$ pulses with a probe sonicator (model 60, Thermo Fisher Scientific, Waltham, MA, USA). In some cases, $1 \%$ Triton $\mathrm{X}-100$ was added to the $0.1 \mathrm{M} \mathrm{HCl}$ in order to lyse the follicles more rapidly. The samples were then heated at $95^{\circ} \mathrm{C}$ for $2 \mathrm{~min}$ and stored at $-80{ }^{\circ} \mathrm{C}$ until assayed.

The approximate cGMP concentration in the follicle was calculated based on an estimated volume of $20 \mathrm{nl}$ for the cellular space of a follicle having an average diameter of $360 \mu \mathrm{m}$ (Norris et al. 2009). Of the $24 \mathrm{nl}$ calculated for a sphere of this diameter, a few nanolitres are occupied by extracellular antral space. It should also be noted that mechanically dissected follicles have an $\sim 10-20 \mu \mathrm{m}$ thick layer of adhering theca cells and debris that is not part of the follicle itself; this $\sim 2-4 \mathrm{nl}$ volume was disregarded. For these reasons, the absolute cGMP concentrations presented in the figures and text should be considered as approximate values.

\section{Immunoblotting}

Follicle samples for immunoblotting were prepared as previously described (Norris et al. 2008). A431 cells treated with EGF (\#sc-2202; Santa Cruz Biotechnology, Santa Cruz, CA, USA) were used as a positive control. Proteins were separated by SDS-PAGE (7.5\% gel) and transferred to a PVDF membrane. Blots were probed with an antibody specific for pY1068 EGFR (\#3777; Cell Signaling Technology, Beverly, MA, USA; 1:1000 dilution in Tris-buffered saline with $0.1 \%$ Tween20 and 5\% BSA) and processed for development with ECL-Plus (GE Healthcare, Piscataway NJ, USA). The blots were stripped with Restore western blot stripping buffer (Thermo Fisher Scientific) and probed with an antibody for total EGFR (\#06-847, Millipore; $10 \mathrm{ng} / \mathrm{ml}$ in Tris-buffered saline with $0.1 \%$ Tween-20 and 5\% BSA). Films were scanned, and the intensity of the $\sim 170 \mathrm{kDa}$ band was measured using ImageJ software (http://rsbweb.nih.gov/ij/). The use of a different antibody against pY1068 EGFR (\#2234; Cell Signaling Technology) showed an effect on the $\sim 170 \mathrm{kDa}$ band that was similar to that shown in Fig. 3B.

\section{Gap junction measurements}

Gap junction permeability was assessed by microinjecting the follicle-enclosed oocyte with $2.5 \mathrm{mM}$ of a $326 \mathrm{kDa}$ fluorescent tracer, Alexa Fluor 350, and imaging the distribution of fluorescence in the follicle at $20 \mathrm{~min}$ after injection, using two-photon microscopy (Norris et al. 2008). The ratio of fluorescence in the mural granulosa cells over that in the inner cumulus cells was used as a measure of gap junction communication (Norris et al. 2008).

\section{Statistical analyses}

Statistical analyses were performed using the Mann-Whitney test function of InStat 3 for Macintosh (GraphPad Software, Inc., La Jolla, CA, USA).

\section{Supplementary data}

This is linked to the online version of the paper at http://dx.doi. org/10.1530/REP-10-0288.

\section{Declaration of interest}

The authors declare that there is no conflict of interest that could be perceived as prejudicing the impartiality of the research reported.

\section{Funding}

This work was supported by the National Institutes of Health (R01 HD014939 to L A Jaffe). The two-photon microscope was supported by grants from the Department of Energy and NIH (RR022232).

\section{Acknowledgements}

We thank Philip Cohen and the National Centre for Protein Kinase Profiling, MRC Protein Phosphorylation Unit, University of Dundee, Scotland, UK (http://www.kinase-screen.mrc.ac. uk), for analyzing the specificity of AG1478. We also thank A F Parlow for providing highly purified ovine $\mathrm{LH}$ and $\mathrm{FSH}$, Will Ratzan, Leia Shuhaibar, Amber Selko, and Mikhail Tsesis for assistance in dissecting follicles, Ann Cowan for making available the two-photon microscope, and Lisa Mehlmann, Melina Schuh, Marco Conti, Mario Ascoli, and John Eppig for helpful discussions.

\section{References}

Andric N \& Ascoli M 2008 The luteinizing hormone receptor-activated extracellularly regulated kinase- $1 / 2$ cascade stimulates epiregulin release from granulosa cells. Endocrinology 149 5549-5556. (doi:10. 1210/en.2008-0618)

Andric N, Thomas M \& Ascoli M 2010 Transactivation of the epidermal growth factor receptor is involved in the lutropin receptor-mediated down-regulation of ovarian aromatase expression in vivo. Molecular Endocrinology 24 552-560. (doi:10.1210/me.2009-0450)

Ashkenazi H, Cao X, Motola S, Popliker M, Conti M \& Tsafriri A 2005 Epidermal growth factor family members: endogenous mediators of the ovulatory response. Endocrinology 146 77-84. (doi:10.1210/en.20040588)

Davis JS, Weakland LL, West LA \& Farese RV 1986 Luteinizing hormone stimulates the formation of inositol trisphosphate and cyclic AMP in rat granulosa cells. Biochemical Journal 238 597-604.

Dekel N \& Sherizly I 1985 Epidermal growth factor induces maturation of rat follicle-enclosed oocytes. Endocrinology 116 406-409. (doi:10.1210/ endo-116-1-406)

Downs SM, Daniel SA \& Eppig JJ 1988 Induction of maturation in cumulus cell-enclosed mouse oocytes by follicle-stimulating hormone and epidermal growth factor: evidence for a positive stimulus of somatic cell origin. Journal of Experimental Zoology 245 86-96. (doi:10.1002/ jez.1402450113)

Eppig JJ, Viveiros MM, Marin Bivens CL \& De La Fuente R 2004 Regulation of mammalian oocyte maturation. In The Ovary, pp 113-129. Eds PCK Leung \& EY Adashi. San Diego, CA: Elsevier/Academic Press.

Hinckley M, Vaccari S, Horner K, Chen R \& Conti M 2005 The G-proteincoupled receptors GPR3 and GPR12 are involved in cAMP signaling and maintenance of meiotic arrest in rodent oocytes. Developmental Biology 287 249-261. (doi:10.1016/j.ydbio.2005.08.019) 
Holt JE, Weaver J \& Jones KT 2010 Spatial regulation of APC ${ }^{\mathrm{Cdh} 1}$-induced cyclin B1 degradation maintains $\mathrm{G}_{2}$ arrest in mouse oocytes. Development 137 1297-1304. (doi:10.1242/dev.047555)

Hsieh M, Lee D, Panigone S, Horner K, Chen R, Theologis A, Lee DC, Threadgill DW \& Conti M 2007 Luteinizing hormone-dependent activation of the epidermal growth factor network is essential for ovulation. Molecular and Cellular Biology 27 1914-1924. (doi:10.1128/MCB.01919-06)

Hubbard CJ 1986 Cyclic AMP changes in the component cells of graafian follicles: possible influences on maturation in the follicle-enclosed oocytes of hamsters. Developmental Biology 118 343-351. (doi:10. 1016/0012-1606(86)90003-5)

Jaffe LA \& Norris RP 2010 Initiation of the meiotic prophase-to-metaphase transition in mammalian oocytes. In Oogenesis: The Universal Process, ch 7, pp 181-197. Eds M-H Verlhac \& A Villeneuve. Chichester, UK: John Wiley \& Sons, Ltd.

Ledent C, Demeestere I, Blum D, Petermans J, Hamalainen T, Smits G \& Vassart G 2005 Premature ovarian aging in mice deficient for Gpr3. PNAS 102 8922-8926. (doi:10.1073/pnas.0503840102)

Levitzki A \& Gazit A 1995 Tyrosine kinase inhibition: an approach to drug development. Science 267 1782-1788. (doi:10.1126/science.7892601)

Marangos P \& Carroll J 2004 The dynamics of cyclin B1 distribution during meiosis I in mouse oocytes. Reproduction 128 1741-7899. (doi:10. 1530/rep.1.00192)

Mehlmann LM 2005 Oocyte-specific expression of Gpr3 is required for the maintenance of meiotic arrest in mouse oocytes. Developmental Biology 288 397-404. (doi:10.1016/j.ydbio.2005.09.030)

Mehlmann LM, Saeki Y, Tanaka S, Brennan TJ, Evsikov AV, Pendola FL, Knowles BB, Eppig J \& Jaffe LA 2004 The $\mathrm{G}_{\mathrm{s}}$-linked receptor GPR3 maintains meiotic arrest in mammalian oocytes. Science 306 1947-1950. (doi:10.1126/science.1103974)

Norris RP, Freudzon M, Mehlmann LM, Cowan AE, Simon AM, Paul DL, Lampe PD \& Jaffe LA 2008 Luteinizing hormone causes MAPKdependent phosphorylation and closure of $\mathrm{Cx} 43$ gap junctions in mouse ovarian follicles: one of two paths to meiotic resumption. Development 135 3229-3238. (doi:10.1242/dev.025494)

Norris RP, Ratzan WJ, Freudzon M, Mehlmann LM, Krall J, Movsesian MA, Wang H, Ke H, Nikolaev VO \& Jaffe LA 2009 Cyclic GMP from the surrounding somatic cells regulates cyclic AMP and meiosis in the mouse oocyte. Development 136 1869-1878. (doi:10.1242/dev.035238)

Oh JS, Han SJ \& Conti M 2010 Wee1B, Myt1, and Cdc25 function in distinct compartments of the mouse oocyte to control meiotic resumption. Journal of Cell Science 188 199-207. (doi:10.1083/jcb. 200907161)
Panigone S, Hsieh M, Fu M, Persani L \& Conti M 2008 LH signaling in preovulatory follicles involves early activation of the EGFR pathway. Molecular Endocrinology 22 924-936. (doi:10.1210/me.2007-0246)

Park JY, Su YQ, Ariga M, Law E, Jin SL \& Conti M 2004 EGF-like growth factors as mediators of LH action in the ovulatory follicle. Science $\mathbf{3 0 3}$ 682-684. (doi:10.1126/science.1092463)

Pincus G \& Enzmann EV 1935 The comparative behavior of mammalian eggs in vivo and in vitro. Journal of Experimental Medicine 62 665-675. (doi:10.1084/jem.62.5.665)

Piontkewitz Y \& Dekel N 1993 Heptanol, an alkanol that blocks gap junctions, induces oocyte maturation. Endocrine Journal 1 365-372.

Sela-Abramovich S, Chorev E, Galiani D \& Dekel N 2005 Mitogenactivated protein kinase mediates luteinizing hormone-induced breakdown of communication and oocyte maturation in rat ovarian follicles. Endocrinology 146 1236-1244. (doi:10.1210/en.2004-1006)

Sela-Abramovich S, Edry I, Galiani D, Nevo N \& Dekel N 2006 Disruption of gap junctional communication within the ovarian follicle induces oocyte maturation. Endocrinology 147 2280-2286. (doi:10.1210/en. 2005-1011)

Su YQ, Denegre JM, Wigglesworth K, Pendola FL, O'Brien MJ \& Eppig JJ 2003 Oocyte-dependent activation of mitogen-activated protein kinase $($ ERK1/2) in cumulus cells is required for the maturation of the mouse oocyte-cumulus cell complex. Developmental Biology 263 126-138. (doi:10.1016/S0012-1606(03)00437-8)

Su Y-Q, Sugiura K, Li Q, Wigglesworth K, Matzuk MM \& Eppig JJ 2010 Mouse oocytes enable LH-induced maturation of the cumulus-oocyte complex via promoting EGF receptor-dependent signaling. Molecular Endocrinology 24 1230-1239. (doi:10.1210/me.2009-0497)

Törnell J, Billig H \& Hillensjö T 1991 Regulation of oocyte maturation by changes in ovarian levels of cyclic nucleotides. Human Reproduction 6 411-422.

Vaccari S, Weeks JL, Hsieh M, Menniti FS \& Conti M 2009 Cyclic GMP signaling is involved in the LH-dependent meiotic maturation of mouse oocytes. Biology of Reproduction 81 595-604. (doi:10.1095/biolreprod. 109.077768)

Received 27 June 2010

First decision 20 July 2010

Accepted 7 September 2010 